\title{
Carbon Nanotubes as Innovative Materials for Bone Grafting Applications
}

ISSN: 2576-9170

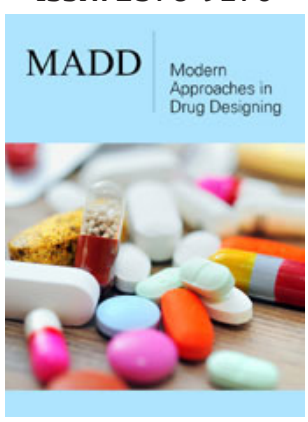

*Corresponding author: Ahmed A Haroun, Chemical Industries Research Division,

National Research Centre, Dokki, Giza, Egypt

Submission: 笽 November 25, 2019

Published: 眥December 13, 2019

Volume 2 - Issue 5

How to cite this article: Ahmed A Haroun. Carbon Nanotubes as Innovative Materials for Bone Grafting Applications. Mod Appro Drug Des.2(5). MADD.000547.2019. DOI: 10.31031/MADD.2019.02.000547.

Copyright@ Ahmed A Haroun, This article is distributed under the terms of the Creative Commons Attribution 4.0 International License, which permits unrestricted use and redistribution provided that the original author and source are credited.

\author{
Ahmed A Haroun* \\ Chemical Industries Research Division, National Research Centre, Dokki, Giza, Egypt
}

\begin{abstract}
When carbon nanotubes (CNTs) stability of the bone tissue affects the formation of bones are important issues. There is also a lot of attention to the impact of CNTs on the bone. "CNTs can be considered as osteoproductive material in terms of bone regeneration, which can produce both intracellular and extracellular cell response on the material surface, which is beneficial in bone regeneration as they facilitate rapid production of bone integration. Multi-walled carbon nanotubes (MWCNTs) have excellent compatibility with bone tissue and help to repair the bone by accelerating its growth. In addition, CNTs are closely integrated without toxic effect in the grown bone. Such results will encourage the design of modalities of clinical treatment involving CNTs. Our previous studies also showed that the MWCNTs/ chitosan/TiO2 nanocomposite manufactured through the technique of solvent evaporation improved implanted material resorption and increased proliferation of bone cells.
\end{abstract}

Keywords: Carbon nanotubes; In vitro bone bioactivity; Cytotoxicity; SBF, Scaffolds; Allografts

\section{Introduction}

Bone is a natural composite material that comprises approximately $45-60 \%$ minerals, 20 $30 \%$ matrix and $10-20 \%$ liquid by weight. Including the water fraction in the organic phase can simply represent the composition of the bone. The matrix is the organic element composed primarily of the Type I collagen protein. The cell portion consists of osteoblasts (bone-forming cells), osteoclasts (bone-destructive cells), osteocytes (bone-preserving cells that are inactive osteoblasts stuck in the extracellular matrix) and bone lining cells (inactive cells that are thought to be precursors of osteoblasts). A calcium phosphate known as hydroxyapatite (HA) is the mineral inorganic element of bone. The chemical structure of hydroxyapatite is described by formula $\mathrm{Ca}_{10}\left[\mathrm{PO}_{4}\right]_{6}[\mathrm{OH}]_{2}[1-3]$. Bone grafts are used when bone is lost due to injury or illness to play both a mechanical and biological function, helping to restore skeletal integrity, fill voids, and improve bone repair. Worldwide, more than 2 million bone grafting procedures are carried out annually. Ninety percent of these procedures used natural bone (from the patient's own body) or allografts (from a corpse) [4]. Because of some restrictions on the use of autographs or allografts, tissue engineering approaches have been used to try to repair bone defects using bioresorbable scaffolds to support cell attachment, migration, proliferation and differentiation [5]. An ideal material for reinforcement would provide the composite with mechanical integrity at low loads, without reducing its bioactivity. Carbon nanotubes (CNTs) have excellent potential to achieve this with their small size, high aspect ratio (length to diameter) and high strength and rigidity. Recent studies have even indicated having such bioactive properties [6-11]. Haroun AA [12]. reported that MWCNTs/ $\beta$-cyclodextrin or MWCNTs/dodecenyl succinic anhydride encapsulated beta vulgaris leaves extract to form bionanocomposites with good antioxidant properties [12,13].

\section{Toxicity of CNTs}

Toxicity, the key drawback of the use of CNTs for bone tissue engineering applications, has effectively reduced the flexibility of the surface. Compared to single walled carbon nanotubes (SWCNTs-COOH) with diameters $(0.5-2 \mathrm{~nm})$ it was found that oxidized multiwalled carbon nanotubes (MWCNTs- $\mathrm{COOH}$ ) with larger diameters $(2-80 \mathrm{~nm})$ better promotes both proliferation and osteogenic differentiation. MWCNTs are shown to be well compatible with bone tissue, enabling bone regeneration and closely integrated with bone tissue. 
Beta-cyclodextrin used previously for functionalization of MWCNTs to minimize their toxicity and enhance the biocompatibility [14] (Figure 1). Besides, Haroun and his coworkers [15], prepared and in vitro bone bioactivity examined of MWCNTs- $\mathrm{COOH}$ after soaking in simulated body fluid (SBF), as a standard tool to test the apatite ability formation [16]. The use of carbon nanotubes as scaffolds for bone regeneration has been evaluated with the aid of Streitzel et al. [17], which reported about MWCNTs containing mouse-implanted human bone morphogenetic protein-2 (rhBMP-2). Also, Rajesh et al. [18] used CNTs to enhance hydroxyapatite that was once inserted in the femur of the rabbit as a bone defect. White et al. [4] validated similar findings, suggesting that CNTS have to be functionalized to decorate their potential for rapid formation of new bones and this used to be evident in our preceding study [19]. However, it can also be suggested that the usage of them as carriers or bettering other bone alternative materials mechanical properties can also yield better results.
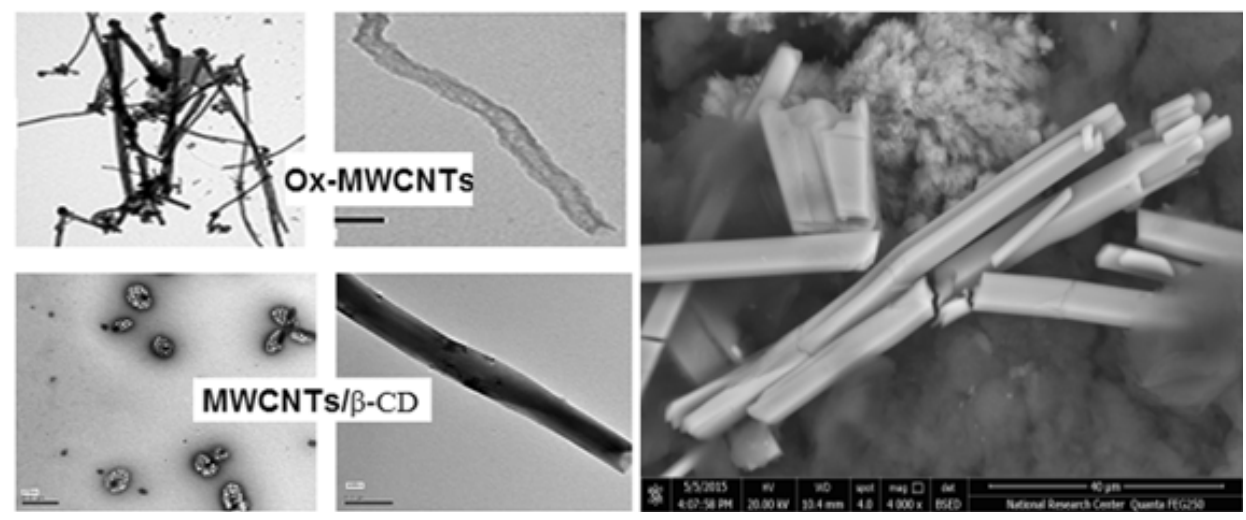

Figure 1: TEM images of functionalized MWCNTs with $\beta$-CD in comparison with oxidized MWCNTs and SEM-micrograph of ox-MWCNTs after soaking in SBF for 7 days.

\section{Conclusion and Future Perspectives}

MWCNTs-based composite substances are gaining multiplied attention as synthetic picks to bone grafting materials. Promising outcomes have been completed indicating that these novel nanomaterials should be recommended their application in tissue engineering after further investigations, in particular in the histological conduct following grafting of CNTs as properly as their cytotoxic consequences on organs and tissues.

\section{Acknowledgment}

The author acknowledges The Egyptian Academy of Science and Technology (ASRT) and Bulgarian Academy of Science (BAS) for supporting through bilateral joint project 2019/2021.

\section{References}

1. McMahon RE, Wang L, Skoracki R, Mathur AB (2013) Development of nanomaterials for bone repair and regeneration. J Biomed Mater Res B Appl Biomater 101(2): 387-397.

2. Suenaga H, Furukawa KS, Suzuki Y, Takato T, Ushida T, et al. (2015) Bone regeneration in calvarial defects in a rat model by implantation of human bone marrow-derived mesenchymal stromal cell spheroids. J Mater Sci Mater Med 26(11): 254.

3. Zimmermann G, Moghaddam A (2011) Allograft bone matrix versus synthetic bone graft substitutes. Injury 42(Supp 2): S16-S21.

4. White AA, Best SM, Ian Kinloch (2007) Hydroxyapatite-carbon nanotube composites for biomedical applications: A review. Int J Appl Ceram Technol 4(1): 1-13.

5. Mesgar AS, Mohammadi Z, Khosrovan S (2018) Improvement of mechanical properties and in vitro bioactivity of freeze-dried gelatin/ chitosan scaffolds by functionalized carbon nanotubes. Int J Polym Mater and Polym Biomater 67(4): 267-276.
6. Pan L, Pei X, He R, Wan Q Wang (2012) Multiwall carbon nanotubes/ polycaprolactone composites for bone tissue engineering application. Colloids Surf B Biointerfaces 93: 226-234.

7. Park S, Park J, Jo I, Cho SP, Sung D, et al. (2015) In situ hybridization of carbon nanotubes with bacterial cellulose for three-dimensional hybrid bioscaffolds. Biomaterials 58: 93-102.

8. Rezwan K, Chen Q Blaker J, Boccaccini A (2006) Biodegradable and bioactive porous polymer/inorganic composite scaffolds for bone tissue engineering. Biomaterials 27(18): 3413-3431.

9. Haroun AA, Amin HA, Abd El-Alim SH (2018) Immobilization and in vitro evaluation of soyasapogenol B onto functionalized multi-walled carbon nanotubes. IRBM 39(1): 35-42.

10. Amin HA, Haroun AA (2017) Comparative studies of free and immobilized Aspergillus flavus onto functionalized multiwalled carbon nanotubes for soyasapogenol B production. Egyptian Pharmaceutical Journal 16(3): 138-143.

11. Haroun AA, Elnahrawy AM, Abd-Alla HI (2017) Sol-gel preparation and in vitro cytotoxic activity of nanohybrid structures based on multi-walled carbon nanotubes and silicate. Inorganic and Nano-Metal Chemistry 47(7): 1023-1027.

12. Haroun AA, Taie HA (2014) Cytotoxicity and antioxidant activity of Beta Vulgaris extract released from grafted carbon nanotubes-based nanocomposites. Macromolecular Symposia 337(1): 25-33.

13. Khaled E, Kamel MS, HNA Hassan, Haroun AA, Youssef AM, et al. (2012) Novel multi walled carbon nanotubes/ $\beta$-cyclodextrin based carbon paste electrode for flow injection potentiometric determination of piroxicam. Talanta 97: 96-102.

14. Haroun AA, Taie HA (2015) Preparation and rational biological evaluation of functionalized carbon nanotubes with plant extracts. Proceeding at $2^{\text {nd }}$ Int Symposium on Mater and Sustainable Development, Algeria.

15. Haroun A, Basma M, Mahmoud S, Reham AAM (2019) Preparation and histological study of multi-walled carbon nanotubes bone graft 
in management of class II furcation defects in dogs. Open Access Macedonian J Medical Sci.

16. Kokubo T, Takadama H (2008) Simulated Body Fluid (SBF) as a standard tool to test the bioactivity of implants. Handbook of Biomineralization: Biological Aspects and Structure Formation. Chapter 51.

17. Streitzel FB, Khongkhunthian P, Khattiya R, Patchanee P, Reichart PA (2006) Healing pattern of bone defects covered by different mmbrane types-A histologic study in the porcine mandible. J Biomed Mater Res 78(1): 35-46.
18. Rajesh R, Senthilkumar N, Hariharasubramanian A, Ravichandran YD (2012) Review on hydroxyapatite-carbon nanotube composites and some of their applications. International Journal of Pharmacy and Pharmaceutical Sciences 4: 23.

19. Haroun AA, Amany AN, Sherine AN, Basma Z (2013) Histological study of novel bone grafts based on $ß$-cyclodextrin/hydroxyapatite for class II furcation defects in dogs. J Applied Sci Research 9 (6): 3820-3833. 